\title{
Anogenital distance is related to ovarian follicular number in young Spanish women: a cross-sectional study
}

\author{
Jaime Mendiola 1,2*, Manuela Roca ${ }^{1,2}$, Lidia Mínguez-Alarcón ${ }^{1}$, Maria-Pilar Mira-Escolano ${ }^{1}$, José J López-Espín \\ Emily S Barrett ${ }^{4}$, Shanna H Swan ${ }^{5}$ and Alberto M Torres-Cantero ${ }^{1,6}$
}

\begin{abstract}
Background: In animals, anogenital distance (AGD) at birth reflects androgen levels during pregnancy and predicts adult AGD. Little is known about AGD in relation to female reproductive characteristics in humans, a question this study was designed to explore.

Methods: We used multiple linear and logistic regression analyses to model the relationships between adult female reproductive system characteristics (e.g. ovarian morphology, menstrual cycle) and two measures of AGD [anus-fourchette $\left(\mathrm{AGD}_{\mathrm{AF}}\right)$ and anus-clitoris $\left(\mathrm{AGD}_{\mathrm{AC}}\right)$ ] in 100 college-age volunteers in Spain. Ovarian morphology was classified as having $<6$ or $\geq 6$ follicles per ovary.

Results: Both AGD measures were positively associated with ovarian follicle number, with $A_{G D}$ AF being more strongly associated. Women in the upper tertile of the $A G D_{A F}$ and $A G D_{A C}$ distributions were more likely to have $\geq 6$ ovarian follicles [OR: $6.0(95 \% \mathrm{Cl} 2.0,17.6)$ and 3.0 (95\% Cl 1.1, 8.6), respectively] compared to women in the lowest tertile.

Conclusions: Increased follicular recruitment has been related to excess androgen exposure in utero in toxicological studies. Our results suggest that the androgenic environment during early fetal life may influence reproductive system development, including AGD, in human females.
\end{abstract}

Keywords: Androgens, Anogenital distance, Increased follicular recruitment, Ovarian morphology

\section{Background}

Anogenital distance (AGD) is routinely used as a developmental endpoint in animal toxicology studies by the U.S. Environmental Protection Agency and is one of the most sensitive markers of in utero exposures to environmental endocrine-disrupting chemicals (EDC) [1,2]. A number of animal studies have shown that exogenous androgen or estrogen exposure (including EDC) during the prenatal period can alter the development of the female reproductive tract [3-15]. For example, bisphenol A (BPA), which may have both estrogenic and anti-androgenic properties, has

\footnotetext{
*Correspondence: jaime.mendiola@um.es

'Division of Preventive Medicine and Public Health, Department of Health and Social Sciences, University of Murcia School of Medicine, Espinardo Campus, Espinardo (Murcia), 30100, Spain

${ }^{2}$ Fertilidad Roca, Gestión Clínica Avanzada SLU, Avenida Ronda Sur 20, Murcia, 30010, Spain

Full list of author information is available at the end of the article
}

been shown to disrupt and alter ovarian function [10-14]; and it has recently been demonstrated that BPA alters early oogenesis and follicle formation in the fetal ovary of nonhuman primates [14]. Moyer and Hixon [15] have recently shown that prenatal exposure to another well-known EDC, di(2-ethylhexyl) phthalate, increased the numbers of mature follicles in adult females in the highest exposure group and the subsequent decrease in overall reproductive lifespan. In rodents, AGD reflects the amount of androgen to which a female fetus is exposed in early development. Indeed, prenatal exposure of females to exogenous androgens results in longer and more masculine AGD [5-7] and increased ovarian follicular recruitment in adulthood compared to controls [3,4,7]. In male rodents, shortened (weightadjusted) AGD persists into adulthood [16] and predicts compromised reproductive function in the mature male
C Biomed Central

(c) 2012 Mendiola et al.; licensee BioMed Central Ltd. This is an Open Access article distributed under the terms of the Creative Commons Attribution License (http://creativecommons.org/licenses/by/2.0), which permits unrestricted use, distribution, and reproduction in any medium, provided the original work is properly cited. 
$[17,18]$. Therefore, in rodents AGD appears to provide a life-long read-out of prenatal androgen action [17].

Swan and colleagues showed a strong inverse association between prenatal environmental exposure to the anti-androgenic phthalates and shorter male AGD in human infants $[19,20]$. Recently, several studies on adult men have provided strong evidence of the relationship between AGD length and male reproductive function $[21,22]$. Thus, AGD may provide a reliable link between prenatal hormonal milieu and adult reproductive function in human males as well. Less is known about AGD in human females, but there are several published reports of virilization of the lower urogenital tract after either prenatal exogenous or endogenous exposure to androgenic hormones [23,24]. Although a number of studies have measured female AGD measurements in human infants [19,20,23,25-27], to our knowledge, no study has measured AGD in adult women. The aim of this study is to investigate the relationship between AGD measures and adult female reproductive system characteristics.

\section{Methods}

\section{Study population}

The Murcia Young Women's Study (MYWS) is a crosssectional study of healthy young university students (18-23 years old) in the Murcia region of Spain. MYWS was carried out between $9^{\text {th }}$ February 2011 and $25^{\text {th }}$ November 2011. Written informed consent was obtained from all subjects. The Research Ethics Committee of the University of Murcia approved this study.

Flyers stating, "Young healthy female university students wanted for research project" were posted at university campuses to invite students to participate in this study. To be included in MYWS, subjects had to be university students, have been born in Spain after $31^{\text {st }}$ December 1987, and be able to contact their mother and ask her to complete a questionnaire. One hundred and twenty-four students contacted us, 15 subjects did not meet inclusion criteria (3 had not been born in Spain and 12 were born before $31^{\text {st }}$ December, 1987), leaving 109 (88\%) eligible students of whom 100 (92\%) agreed to participate in the study. At a scheduled clinic visit subjects underwent a gynecological examination, including transvaginal ultrasound, and completed an epidemiological questionnaire on lifestyle. Participants were compensated for their participation ( $€ 40$ gift card).

\section{Physical examination and gynecological history}

Body weight and height were measured using a digital scale (Tanita SC 330-S, London, UK). Body mass index (BMI) was calculated as weight in kilograms divided by squared height in meters. Ovarian and uterine morphology were studied by transvaginal ultrasound using a single ultrasound machine for all imaging studies (Voluson $\mathrm{E} 8{ }^{\circledR}$; General Electric Healthcare, USA). Women were scanned in the early follicular phase (cycle days 1-6) by two gynecologists (75\% by M.R. and $25 \%$ by C.M.) using the same classification.

Uterine morphology was assessed as normal or abnormal. Ovaries were classified as having $<6$ or $\geq 6$ follicles per ovary [28-30], a cutoff which several studies suggest may have clinical relevance [28,29]. All follicles fell in the $2-10 \mathrm{~mm}$ diameter range. Having 6 or more follicles has been associated with hyperprolactinaemia, hypothalamic anovulation or weight-related amenorrhoea and may result from incomplete pulsatile gonadotrophin (GnRH) stimulation of ovarian follicular development [28]. It may also indicate an ovarian dysfunction in female adolescents with cystic fibrosis [29] or the presence of polycystic ovary [30].

In addition, a complete gynecological history was obtained from each subject, including history of gynecological diseases (salpingitis, endometriosis, other) (yes/no), self-reported menstrual cycle length (days) and previous irregular menstrual cycle (yes/no).

\section{Anogenital measurements}

For each subject, AGD was measured in two ways. First, $\mathrm{AGD}_{\mathrm{AC}}$ was measured from the anterior clitoral surface to the center of the anus (Figure 1, point 1 to point 3 ). Second, $A G D_{A F}$ was measured from the posterior fourchette to the center of the anus (Figure 1, point 2 to point 3). Measurements were made using a digital caliper (Stainless Steel Digital Caliper, VWR ${ }^{\circledR}$ International, LLC, West Chester, PA, USA) and while subjects were in the lithotomy position, with the thighs at a $45^{\circ}$ angle

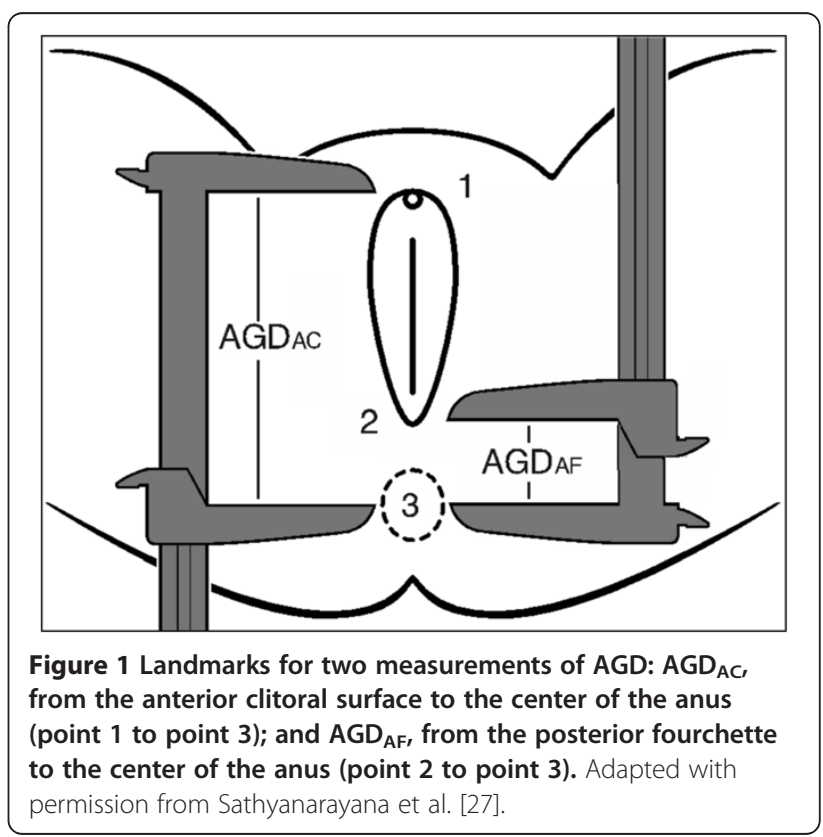


to the examination table. To improve precision, two examiners made each of these measurements three times, taking in total 6 measures for $\mathrm{AGD}_{\mathrm{AF}}$ and $A_{G D_{A C}}$, respectively. The mean of the six measurements was used as the estimate. Neither the examiners nor the support staff had knowledge of any of the women's possible conditions/alterations because the AGD measures were taken before the gynecological examination.

\section{Statistical analyses}

We assessed intra- and inter-examiner variability in the AGD measurements by calculating the coefficient of variation (\% CV). We used multiple linear regression analyses to identify predictors of each of the two AGD measurements. Covariates initially examined as predictors of AGD measurements were: age, height, weight, body mass index $\left(\mathrm{BMI} ; \mathrm{kg} / \mathrm{m}^{2}\right)$, age at menarche, self-reported sexually transmitted diseases (STD), taking any medication (antibiotics or antihistamines; yes/no) and hormonal contraception (yes/no). When inclusion of a potential covariate resulted in a change in the $\beta$ - coefficient of $<10 \%$, the variable was not retained in final models. Adjusted odds ratios (ORs) and $95 \%$ confidence intervals (CIs) were calculated using logistic regression. All tests were two-tailed and the level of statistical significance was set at 0.05. Statistical analyses were performed with the statistical package IBM SPSS 20.0 (IBM Corporation, Armonk, New York, USA).

\section{Results}

Table 1 shows the general characteristics of young women attending the MYWS. The MYWS study population was quite homogeneous. Participants were nulliparous, mostly in good or excellent health, with neither self-reported STD, nor injuries in the genital region, nor transfusions. None of the women had been diagnosed with salpingitis or endometriosis. Only one woman presented abnormality of the uterus (bicornuate uterus). Sixty-five percent of the young women reported having ever had irregular menstrual cycles. In terms of ovarian morphology, $43 \%$ of the women presented $<6$ ovarian follicles and $57 \% \geq 6$ ovarian follicles. Women with $<6$ follicles had a mean $[ \pm$ standard deviation $(\mathrm{SD})] \mathrm{AGD}_{\mathrm{AF}}$ of $35.3(5.3) \mathrm{mm}$ and $\mathrm{AGD}_{\mathrm{AC}}$ of $77.3(9.7) \mathrm{mm}$. Women with $\geq 6$ follicles had a mean $\mathrm{AGD}_{\mathrm{AF}}$ of $39.4(6.5) \mathrm{mm}$ and $\mathrm{AGD}_{\mathrm{AC}}$ of 82.6 (10.7) $\mathrm{mm}$.

The distributions of both $\mathrm{AGD}_{\mathrm{AC}}$ and $\mathrm{AGD}_{\mathrm{AF}}$ were approximately normal (Figure 2a,b). As expected, $\mathrm{AGD}_{\mathrm{AC}}$ and $\mathrm{AGD}_{\mathrm{AF}}$ were correlated [Pearson correlation $(\mathrm{r})=0.44$, $\mathrm{p}<0.0001]$ (Figure 3). In the multivariate analyses, there was a significant positive association between BMI and both AGD measures (both $\mathrm{p}<0.01$ ). Hormonal contraception was associated with shorter AGD measurements (both $\mathrm{p}<0.05$ ) (Table 2). None of the other covariates were significantly associated with either AGD measurement.
Table 1 Characteristics of young women participating in the Murcia Young Women's Study (MYWS) ${ }^{(1)}$

\begin{tabular}{|c|c|c|}
\hline & Mean (SD) & Median (5-95) \\
\hline Age (years) & $20.0(1.2)$ & $20.0(18.0-22.0)$ \\
\hline $\mathrm{BMI}\left(\mathrm{kg} / \mathrm{m}^{2}\right)$ & $21.8(3.1)$ & $21.3(17.7-28.8)$ \\
\hline Age at menarche & $12.7(1.3)$ & $13.0(11.0-15.0)$ \\
\hline Day of cycle at clinic & $3.9(2.6)$ & $3.5(1.0-6.0)$ \\
\hline Menstrual cycle length ${ }^{a}$ & $30.9(7.6)$ & $30(25.0-44.0)$ \\
\hline Anogenital distance $\left(\mathrm{AGD}_{\mathrm{AC}}\right)(\mathrm{mm})$ & $80.4(10.5)$ & $79.2(59.5-96.1)$ \\
\hline Anogenital distance $\left(\mathrm{AGD}_{\mathrm{AF}}\right)(\mathrm{mm})$ & $37.7(6.3)$ & $37.2(27.9-48.6)$ \\
\hline $\mathrm{AGD}_{\mathrm{AF}} / \mathrm{AGD}_{\mathrm{AC}}$ & $0.47(0.09)$ & $0.46(0.36-0.60)$ \\
\hline & \multicolumn{2}{|c|}{ Percentage of women (\%) } \\
\hline Caucasian & \multicolumn{2}{|c|}{98.0} \\
\hline Cigarette smoking ${ }^{\mathrm{b}}$ & \multicolumn{2}{|c|}{34.0} \\
\hline Alcohol intake (liquor) $)^{c}$ & \multicolumn{2}{|c|}{31.6} \\
\hline \multicolumn{3}{|l|}{ Have had: } \\
\hline Good or excellent general health ${ }^{d}$ & \multicolumn{2}{|c|}{92.0} \\
\hline Diabetes or thyroid disease & \multicolumn{2}{|c|}{2.0} \\
\hline Using hormonal contraception ${ }^{\mathrm{e}}$ & \multicolumn{2}{|c|}{39.8} \\
\hline
\end{tabular}

1) One woman with no physical examination performed $(n=99)$.

a) in days (number of subjects $=36$ ).

b) Mean number \pm (SD) of cigarettes per week, $39.4 \pm$ (29.9), if a smoker.

c) Mean number \pm (SD) of drinks (330 cc) per week, $2.6 \pm(2.5)$, if a drinker.

d) Question was 'How would you describe your own health?

e) Oral contraceptives or vaginal ring.

$\mathrm{SD}=$ Standard deviation; $(5-95)=5^{\text {th }}-95^{\text {th }}$ percentile.

$A G D_{A C}$ : Anogenital Distance from the center of the anus to the anterior clitoral surface.

$A G D_{A F}$ : Anogenital Distance from the center of the anus to the posterior fourchette.

As seen in Table 3, both $\mathrm{AGD}_{\mathrm{AF}}$ and $\mathrm{AGD}_{\mathrm{AC}}$ were positively associated with the presence of $\geq 6$ ovarian follicles. We also examined the association between having $<6$ or $\geq 6$ ovarian follicles and both AGD measurements stratified in tertiles (33 women in each group). Both AGD measures were significantly associated with having $\geq 6$ ovarian follicles after controlling for the same covariates used in the linear regression models. Women with AGD in the upper tertile of the $\mathrm{AGD}_{\mathrm{AC}}$ distribution, compared to the lowest tertile were more likely to have $\geq 6$ ovarian follicles compared to $<6$ follicles (Odds ratio: 3.0, 95\% CI 1.1, 8.6). Similarly, women in the middle and upper tertiles of the $\mathrm{AGD}_{\mathrm{AF}}$ distribution, compared to the lowest tertile, were three and six times more likely to have $\geq 6$ ovarian follicles compared to $<6$ follicles [Odds ratio: 3.2 (95\% CI 1.1, 8.8) and 6.0 (95\% CI 2.0, 17.6), respectively]. Neither AGD measurement was statistically significantly associated with any of the other reproductive outcomes.

\section{Within and between-examiner variability}

Intra-examiner coefficients of variation for both AGD measurements were below 3\%, and inter-examiner coefficients of variation for $\mathrm{AGD}_{\mathrm{AC}}$ and $\mathrm{AGD}_{\mathrm{AF}}$ were $4.9 \%$ 

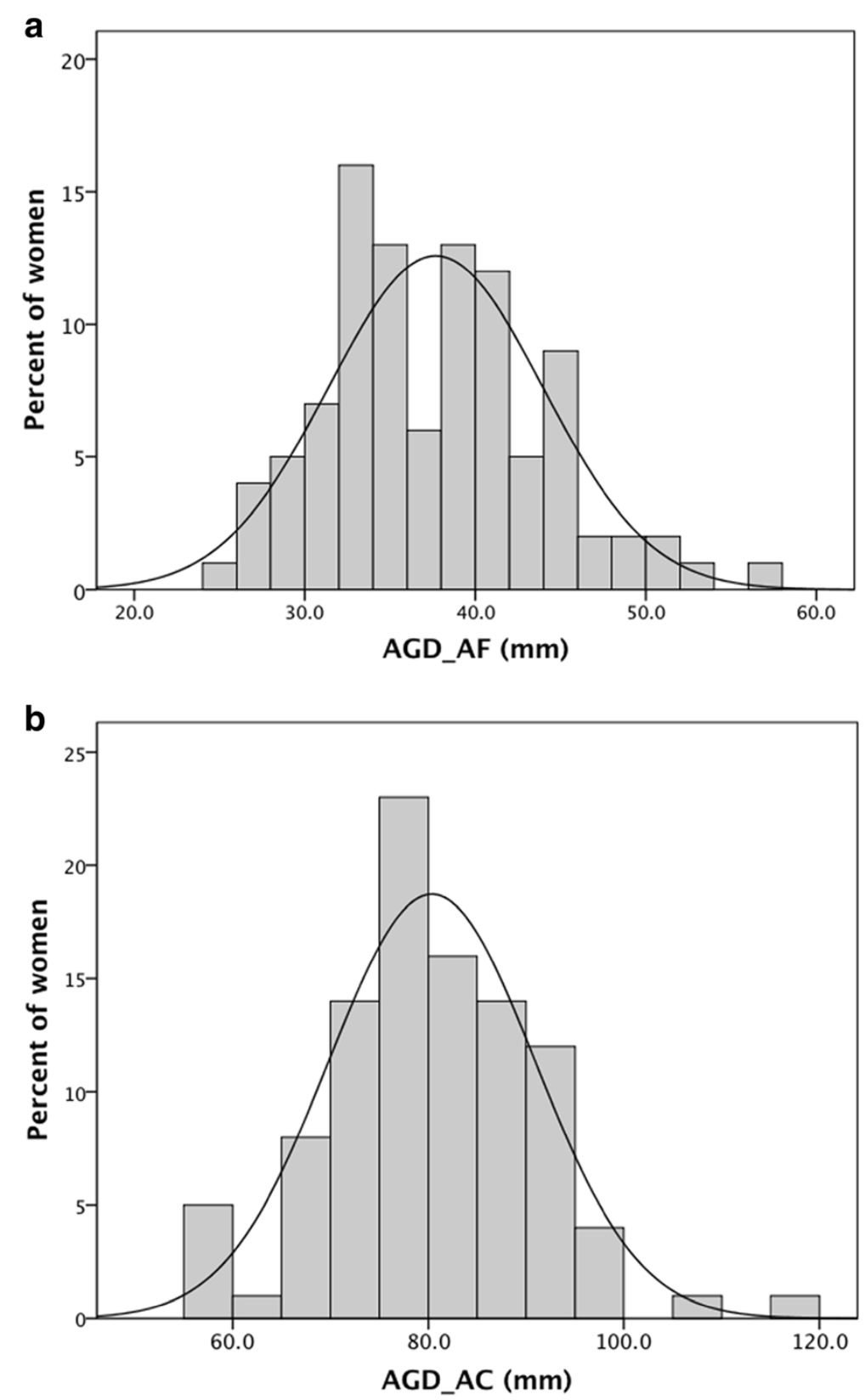

Figure 2 Frequency distributions of (a) $A G D_{A F}$ and (b) $A G D_{A C}$ in the MYWS.

and $10 \%$, respectively. Using a mixed model, the interclass correlations were 0.84 (95\% CI 0.76, 0.89) and 0.61 (95\% CI 0.41, 0.74) for $\mathrm{AGD}_{\mathrm{AC}}$ and $\mathrm{AGD}_{\mathrm{AF}}$, respectively.

\section{Discussion}

This is the first study to measure AGD in adult women and examine the relationships between AGD and female reproductive system characteristics. Both AGD measures were positively and strongly associated with the presence of greater ovarian follicular number. Moreover, a woman with $\mathrm{AGD}_{\mathrm{AC}}$ or $\mathrm{AGD}_{\mathrm{AF}}$ in the highest tertile of the distribution was 3 and 6 times, respectively, as likely to have $\geq 6$ ovarian follicles as a woman with an $\mathrm{AGD}_{\mathrm{AC}}$ or $\mathrm{AGD}_{\mathrm{AF}}$ in the lowest tertile. This underscores the possible clinical implications of the associations that we are reporting here.

Although we typically find that in men AGD measurements are not sensitive to physiologic and lifestyle factors [22], in the current study population the use of hormonal contraception was associated with shorter measures in both AGD measurements ( $p$ values <0.05). One immediate consequence of that finding is that, in 


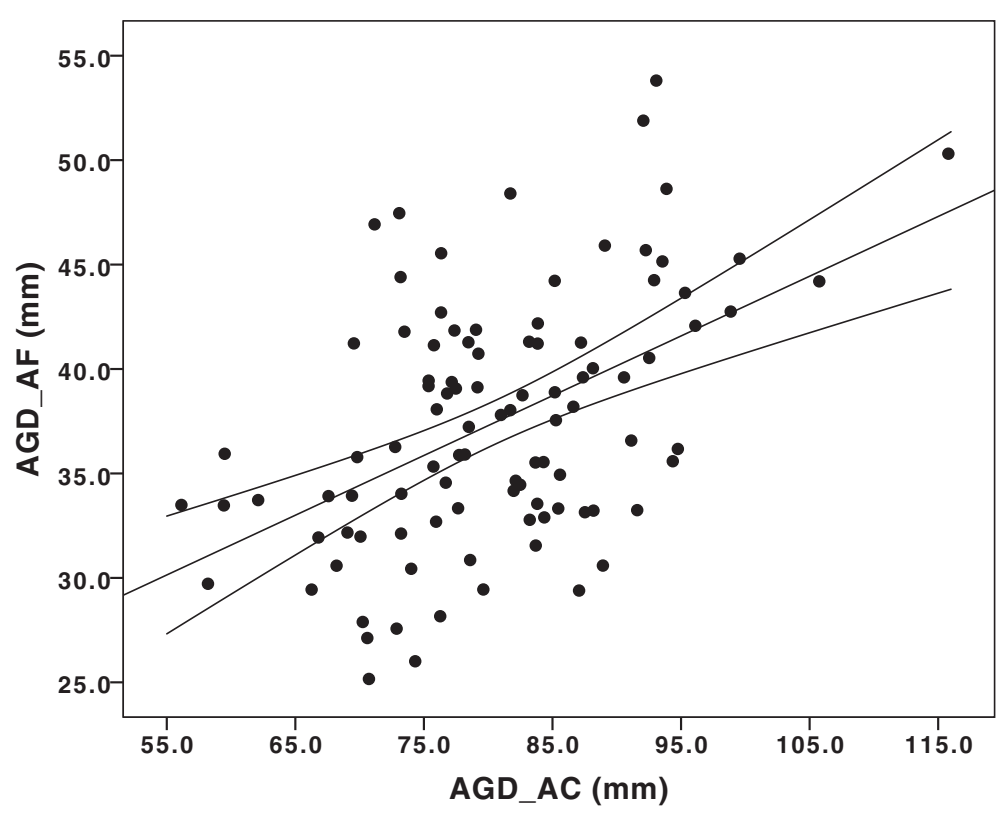

Figure 3 Correlations between $A G D_{A F}$ and $A G D_{A C}$ measures in the MYWS.

females, it may be necessary to control not only for body size (height or BMI) as in men, but also for hormonal status in studies seeking associations with AGD measurements. In our study population, $74 \%(n=29)$ of the young women taking hormonal contraception reported irregular menstrual cycles in the previous three months. However, no association was found between AGD measurements and irregular menstrual cycle. Therefore we could speculate that hormonal intake might be related to the AGD measurements. To our knowledge, this is the first time this association has been reported in humans.

Recently, Dusek and Bartos [31] examined the effect of the stage of the oestrous cycle on the AGD in female mice and showed that AGD varied during the oestrous cycle, and suggesting that female genital morphology systematically varied within the oestrous cycle. Unfortunately, all the AGD measures in our study were taken during the early follicular phase, so that we cannot assess that hypothesis. Nonetheless, it opens a door to the possibility that hormonal changes (including hormonal contraception) could result in small fluctuations in the morphology of the female external genitalia. Longitudinal study measuring AGD within women at multiple points in the cycles is needed to address this possibility.

Alternatively, it has been suggested that women using hormonal contraception are somewhat more fertile than women who do not [32]. In many mammalian species females with shorter AGD are more fertile [33,34]. Therefore, it is possible that the shorter AGD we observed in women using hormonal contraceptives reflects increased fertility, rather than a direct effect of hormone use on AGD.

As multiple animal studies have shown, the female reproductive tract is susceptible to virilization by exogenous androgen exposure prior to, as well as during, the in utero masculinization programming window (MPW) [5-7]. This prenatal hyperandrogenism results in enlarged cystic ovaries, anovulation or increases ovarian follicular recruitment in female offspring $[3,4,7,35]$. Excessive prenatal androgens (either endogenous or exogenous) can produce a polycystic ovary syndrome (PCOS)-like phenotype in

Table 2 Variables related to $A G D_{A F}$ and $A G D_{A C}$ in multivariate models

\begin{tabular}{|c|c|c|c|c|c|c|}
\hline \multirow[t]{2}{*}{ Variable } & \multicolumn{3}{|c|}{$\mathrm{AGD}_{\mathrm{AF}}$} & \multicolumn{3}{|c|}{$A_{G D} D_{A C}$} \\
\hline & $\begin{array}{l}\text { Unstandardized } \\
\text { coefficients }\end{array}$ & $\begin{array}{c}\text { Standardized } \\
\text { coefficients }\end{array}$ & $\begin{array}{c}\mathrm{P}- \\
\text { value }\end{array}$ & $\begin{array}{l}\text { Unstandardized } \\
\text { coefficients }\end{array}$ & $\begin{array}{c}\text { Standardized } \\
\text { coefficients }\end{array}$ & $\begin{array}{c}P- \\
\text { value }\end{array}$ \\
\hline & $\beta$ & $\beta$ & & $\beta$ & $\beta$ & \\
\hline $\mathrm{BMI}\left(\mathrm{kg} / \mathrm{m}^{2}\right)$ & 0.82 & 0.41 & $<0.01$ & 1.2 & 0.34 & $<0.01$ \\
\hline $\begin{array}{l}\text { Hormonal } \\
\text { contraception }\end{array}$ & -2.4 & -0.20 & 0.03 & -4.9 & -0.24 & 0.01 \\
\hline
\end{tabular}

${ }^{a}$ no vs. yes. 
Table 3 Multivariate analysis for young women's female reproductive system characteristics and $A_{G D} D_{A F}$ and $A_{G D}^{(1)}$

\begin{tabular}{|c|c|c|c|c|c|c|c|c|}
\hline \multirow[t]{2}{*}{ Variable } & \multicolumn{4}{|c|}{$\mathrm{AGD}_{\mathrm{AF}}$} & \multicolumn{4}{|c|}{$A G D_{A C}$} \\
\hline & $\beta$ & $95 \% \mathrm{Cl}$ & P-value & $\mathrm{R}^{2}$ & $\beta$ & $95 \% \mathrm{Cl}$ & P-value & $\mathrm{R}^{2}$ \\
\hline Uterine morphology $^{a}$ & -2.0 & $(-9.7,5.7)$ & 0.60 & 0.22 & 1.0 & $(-12.6,14.6)$ & 0.88 & 0.18 \\
\hline \multicolumn{9}{|l|}{ Ovarian morphology } \\
\hline$<6$ ovarian follicles & Ref. & & & & Ref. & & & \\
\hline$\geq 6$ ovarian follicles & 3.1 & $(0.96,5.3)$ & $<0.01$ & 0.30 & 4.6 & $(0.76,8.5)$ & 0.02 & 0.23 \\
\hline Menstrual cycle length ${ }^{b}$ & 0.25 & $(-0.24,0.74)$ & 0.31 & 0.20 & 0.46 & $(-0.62,1.5)$ & 0.39 & 0.23 \\
\hline Irregular menstrual cycle ${ }^{c}$ & 0.69 & $(-1.6,2.9)$ & 0.55 & 0.22 & 0.71 & $(-3.3,4.8)$ & 0.73 & 0.18 \\
\hline
\end{tabular}

1) Controlling for BMI and hormonal contraception.

a) normal/abnormal.

b) in days (number of subjects $=36$ ).

c) Question was: "Have you ever had an irregular menstrual cycle?" (yes/no). $\beta=$ Regression coefficient; $\mathrm{Cl}=$ Confidence interval.

Ref.: reference group.

animal models, furthermore [35,36]. As such, it has been widely hypothesized that the etiology of PCOS in humans may include excess prenatal androgen exposure [37]. Pregnant women with PCOS have elevated circulating concentrations of androgens at mid-gestation, which may increase fetal androgen exposure, and female offspring of PCOS mothers are at increased risk of altered ovarian development and function [38,39]. Long-term follow-up studies are required to determine whether this excessive exposure resulted in long-term changes in ovarian function and/or alterations in reproductive function. Here, we do not examine PCOS per se, however we do demonstrate that AGD, a purported biomarker of prenatal androgen exposure, is associated with increased ovarian follicle number.

With regard to reproducibility of follicle count estimated by transvaginal ultrasound, it has been shown that determination of follicle count by transvaginal ultrasound results in acceptable intra- and inter- observer variability [40]. While there is undoubtedly some inter-cycle variability of follicle count, it is considered to be of little clinical significance, for example, in predicting the response in in vitro fertilization [41]. Several articles have previously defined having $\geq 6$ or $>12$ ovarian follicles as multifollicular [28,29] or polycystic ovaries [30], respectively. We were unable to look at women with polycystic ovaries separately due to small numbers; only 10 women met this criterion. We chose instead to use the cutoff for multifollicular ovary $(\geq 6)$, a cutoff which several studies suggest may have clinical relevance [28-30].

We found significant positive associations between both $\mathrm{AGD}_{\mathrm{AF}}$ and $\mathrm{AGD}_{\mathrm{AC}}$ and the presence of greater ovarian follicle number, which could indicate a common fetal origin between longer AGD and greater follicular recruitment. In fact, in animal models, an association between prenatal exposures to androgen excess and an increase in ovarian follicular recruitment $[3,4,7]$ and longer AGD measurement [7] has been reported.
All previous published studies on human female infants have measured both $\mathrm{AGD}_{\mathrm{AF}}$ and $\mathrm{AGD}_{\mathrm{AC}}$ [19,20,23,25-27]. Callegari et al. [23] also calculated the ratio (i.e.: $\mathrm{AGD}_{\mathrm{AF}} / \mathrm{AGD}_{\mathrm{AC}}$ ) both, in premature/full-term newborn infants and newborn infant girls with congenital adrenal hyperplasia, reporting a relatively higher ratio among subjects with that condition. This result supports the hypothesis that androgen exposure in utero may affect measures of the anogenital region in human females. Callegari et al. [23] also took both AGD measurements on a small number of pregnant women $(n=10)$, reporting the first such data, to the best of our knowledge. With all the possible limitations regarding study population and methodologies, our young women presented longer $\mathrm{AGD}_{\mathrm{AF}}$ and shorter $\mathrm{AGD}_{\mathrm{AC}}$ compared to those ten pregnant women.

We had only a few cases of clinically diagnosed PCOS in our study population; therefore we were unable to explore the relationship between that condition and the AGD measures. A larger and more diverse population or another type of study design (case-control) would add much more information on whether androgen action during early fetal life exerts a fundamental influence on the female reproductive tract in humans, as has been demonstrated in rodents.

Our population was small and limited in age and ethnicity, and thus cannot provide normative values for human female AGD measurements. AGD measures were well tolerated by all subjects, quick to perform, with acceptable intra- and inter-examiner reliability. We plan to assess reproductive hormones in a future publication. A finding of higher FSH and/or low inhibin-B, estradiol or free testosterone with shorter or longer AGD would lend support to the association between AGD and female reproductive system characteristics reported here.

In human males, shorter AGD in adulthood has been associated with poorer semen quality $[21,22]$ and 
infertility [21] suggesting a common origin, including a disruption of testicular development in utero, as suggested by the testicular dysgenesis syndrome hypothesis $[42,43]$. As hypothesized, this syndrome, although potentially multifactorial, may be caused by exposure to EDC during the MPW [18].

Recently, Buck Louis et al. [44] suggested a similar paradigm for human females, the ovarian dysgenesis syndrome, which the authors define as alterations in ovarian structure or function that may manifest as fecundity impairments, gynecologic disorders, gravid diseases or later onset of adult diseases. Environmental exposures, particularly EDC, may be related to in utero origin of gynecologic outcomes, which in turn would be associated with later onset of adult diseases.

\section{Conclusions}

Animal studies have shown that the female reproductive tract is susceptible to virilization by exogenous androgen exposure prior to, as well as during, the MPW that is determined by androgen action [6]. Our data demonstrate associations between the two measurements of AGD we examined and an increase in ovarian follicle number. Our results suggest, therefore, that the androgenic environment during early fetal life may exert a fundamental influence on both AGD and female reproductive system characteristics in humans.

If AGD (adjusted for body size) is determined prenatally in humans as in rodents, a longer female AGD in adulthood should reflect a longer AGD at birth, which in turn may reflect increased androgen exposure in utero. Therefore, both greater follicular recruitment and longer AGD in adulthood - assuming that AGD is a stable finding in humans throughout their lives - may reflect a common origin in utero, resulting in alterations of the developing female reproductive tract.

\footnotetext{
Abbreviations

AGD: Anogenital distance; $A G D_{A C}$ : Anogenital Distance from the center of the anus to the anterior clitoral surface; $A_{G D}$ AF: Anogenital Distance from the center of the anus to the posterior fourchette; BMI: Body mass index; BPA: Bisphenol A; EDC: Endocrine-disrupting chemicals; MPW: Masculinization programming window; MYWS: Murcia Young Women's Study; PCOS: Polycystic ovary syndrome; STD: Sexually transmitted diseases.
}

\section{Competing interests}

The author(s) declared no conflicts of interest with respect to the authorship and/or publication of this article.

\section{Authors' contributions}

MR, JM, SHS and AMTC designed and initiated the current study. MR, LMA and JM were responsible for collecting the samples and the interview data. LMA and MR coordinated the current study. JJLE and MPME were responsible for statistical analysis. ESB, MPME, JM, MR, SHS and AMTC were responsible for writing the draft version of manuscript. All authors commented on and approved the final manuscript.

\section{Acknowledgements}

This work was supported by "Fundación Séneca, Región de Murcia, Agencia Regional de Ciencia y Tecnología, grant no. 08808/PI/08", "Ministerio de
Ciencia e Innovación, Instituto de Salud Carlos III (FIS) grant no PI10/00985" and a research grant from Gestión Clínica Avanzada SLU. The authors gratefully acknowledge Dr. C. Millán, L. Sarabia, C. Ruiz, E. Belmonte and all the USP Dexeus Murcia clinic staff for their assistance in data collection; and the young women of the study for their participation. We also thank K.J. Ruiz-Ruiz and E. Estrella for their work on database management. In memory of our beloved friend and colleague, Maria Fuensanta Mas Tornel.

\section{Author details}

${ }^{1}$ Division of Preventive Medicine and Public Health, Department of Health and Social Sciences, University of Murcia School of Medicine, Espinardo Campus, Espinardo (Murcia), 30100, Spain. ²Fertilidad Roca, Gestión Clínica Avanzada SLU, Avenida Ronda Sur 20, Murcia, 30010, Spain. ${ }^{3}$ Center of Operations Research, Miguel Hernandez University, Elche Campus, Elche, 03202, Spain. ${ }^{4}$ Department of Obstetrics and Gynecology, School of Medicine and Dentistry, University of Rochester, 601 Elmwood Avenue, Rochester (NY), 14624, USA. ${ }^{5}$ Department of Preventive Medicine, Mount Sinai School of Medicine, 1 Gustave L. Levy Place, New York (NY), 10029, USA. ${ }^{6}$ Regional Campus of International Excellence "Campus Mare Nostrum", University of Murcia, Avenida Teniente Flomesta 5, Murcia, 30003, Spain.

Received: 5 November 2012 Accepted: 5 December 2012 Published: 8 December 2012

\section{References}

1. Foster PM: Disruption of reproductive development in male rat offspring following in utero exposure to phthalate esters. Int J Androl 2006, 29:140-147.

2. Gray LE Jr, Wilson VS, Stoker T, Lambright C, Furr J, Noriega N, Howdeshell K, Ankley GT, Guillette L: Adverse effects of environmental anti-androgens and androgens on reproductive development in mammals. Int J Androl 2006, 29:96-104.

3. Smith P, Steckler TL, Veiga-Lopez A, Padmanabhan V: Developmental programming: differential effects of prenatal testosterone and dihydrotestosterone on follicular recruitment, depletion of follicular reserve, and ovarian morphology in sheep. Biol Reprod 2009, 80:726-736.

4. Steckler T, Wang J, Bartol FF, Roy SK, Padmanabhan V: Fetal programming: prenatal testosterone treatment causes intrauterine growth retardation, reduces ovarian reserve and increases ovarian follicular recruitment. Endocrinology 2005, 146:3185-3193.

5. Wolf CJ, Hotchkiss A, Ostby JS, LeBlanc GA, Gray LE Jr: Effects of prenatal testosterone propionate on the sexual development of male and female rats: a dose-response study. Toxicol Sci 2002, 65:71-86.

6. Dean A, Smith LB, Macpherson S, Sharpe RM: The effect of dihydrotestosterone exposure during or prior to the masculinization programming window on reproductive development in male and female rats. Int J Androl 2012, 35:330-339.

7. Wu XY, Li ZL, Wu CY, Liu YM, Lin H, Wang SH, Xiao WF: Endocrine traits of polycystic ovary syndrome in prenatally androgenized female SpragueDawley rats. Endocr J 2010, 57:201-209.

8. Guillette $L J \mathrm{Jr}$, Moore BC: Environmental contaminants, fertility, and multioocytic follicles: a lesson from wildlife? Semin Reprod Med 2006, 24:134-141.

9. Karavan JR, Pepling ME: Effects of estrogenic compounds on neonatal oocyte development. Reprod Toxicol 2012, 34:51-56.

10. Zhang HQ, Zhang XF, Zhang LJ, Chao HH, Pan B, Feng YM, Li L, Sun XF, Shen W: Fetal exposure to bisphenol A affects the primordial follicle formation by inhibiting the meiotic progression of oocytes. Mol Biol Rep 2012, 39:5651-5657.

11. Hunt PA, Koehler KE, Susiarjo M, Hodges CA, llagan A, Voigt RC, Thomas S, Thomas BF, Hassold TJ: Bisphenol A exposure causes meiotic aneuploidy in the female mouse. Curr Biol 2003, 13:546-553.

12. Rivera OE, Varayoud J, Rodríguez HA, Muñoz-de-Toro M, Luque EH: Neonatal exposure to bisphenol A or diethylstilbestrol alters the ovarian follicular dynamics in the lamb. Reprod Toxicol 2011, 32:304-312.

13. Rodríguez HA, Santambrosio N, Santamaría CG, Muñoz-de-Toro M, Luque $\mathrm{EH}$ : Neonatal exposure to bisphenol A reduces the pool of primordial follicles in the rat ovary. Reprod Toxicol 2010, 30:550-557.

14. Hunt PA, Lawson C, Gieske M, Murdoch B, Smith H, Marre A, Hassold T, Vandevoort CA: Bisphenol A alters early oogenesis and follicle formation 
in the fetal ovary of the rhesus monkey. Proc Natl Acad Sci USA 2012, 109:17525-17530.

15. Moyer B, Hixon ML: Reproductive effects in F1 adult females exposed in utero to moderate to high doses of mono-2-ethylhexylphthalate (MEHP). Reprod Toxicol 2012, 34:43-50.

16. Hotchkiss AK, Parks-Saldutti LG, Ostby JS, Lambright C, Furr J, Vandenbergh $J G$, Gray LE Jr: A mixture of the "anti-androgens" linuron and butyl benzyl phthalate alters sexual differentiation of the male rat in a cumulative fashion. Biol Reprod 2004, 71:1852-1861.

17. Macleod DJ, Sharpe RM, Welsh M, Fisken M, Scott HM, Hutchison GR, Drake $\mathrm{AJ}$, van den Driesche S: Androgen action in the masculinization programming window and development of male reproductive organs. Int J Androl 2010, 33:279-287.

18. Scott HM, Hutchison GR, Jobling MS, McKinnell C, Drake AJ, Sharpe RM: Relationship between androgen action in the "male programming window", fetal Sertoli cell number, and adult testis size in the rat. Endocrinology 2008, 149:5280-5287.

19. Swan SH, Main KM, Liu F, Stewart SL, Kruse RL, Calafat AM, Mao CS, Redmon JB, Ternand CL, Sullivan S, Teague $J$, Study for Future Families Research Team: Study for future families research team: decrease in anogenital distance among male infants with prenatal phthalate exposure. Environ Health Perspect 2005, 113:1056-1061.

20. Swan SH: Environmental phthalate exposure in relation to reproductive outcomes and other health endpoints in humans. Environ Res 2008, 108:177-184.

21. Eisenberg ML, Hsieh MH, Walters RC, Krasnow R, Lipshultz LI: The relationship between anogenital distance, fatherhood, and fertility in adult men. PLoS One 2011, 6:e18973.

22. Mendiola J, Stahlhut RW, Jørgensen N, Liu F, Swan SH: Shorter anogenital distance predicts poorer semen quality in young men in Rochester New york. Environ Health Perspect 2011, 119:958-963.

23. Callegari C, Everett S, Ross M, Brasel JA: Anogenital ratio: measure of fetal virilization in premature and full-term newborn infants. J Pediatr 1987 111:240-243.

24. Goldman AS, Bongiovanni AM: Induced genital anomalies. Ann N Y Acad Sci 1967, 142:755-767.

25. Salazar-Martinez E, Romano-Riquer P, Yanez-Marquez E, Longnecker MP, Hernandez-Avila M: Anogenital distance in human male and female newborns: a descriptive, cross-sectional study. Environ Health 2004, 3:8.

26. Phillip M, De Boer C, Pilpel D, Karplus M, Sofer S: Clitoral and penile sizes of full term newborns in two different ethnic groups. J Pediatr Endocrinol Metab 1996, 9:175-179.

27. Sathyanarayana S, Beard L, Zhou C, Grady R: Measurement and correlates of ano-genital distance in healthy, newborn infants. Int J Androl 2010, 33:317-323.

28. Adams J, Franks S, Polson DW, Mason HD, Abdulwahid N, Tucker M, Morris DV, Price J, Jacobs HS: Multifollicular ovaries: clinical and endocrine features and response to pulsatile gonadotropin releasing hormone. Lancet 1985, 2:1375-1379.

29. Galli-Tsinopoulou A, Moudiou T, Mamopoulos A, Karamouzis M, NousiaArvanitakis S: Multifollicular ovaries in female adolescents with cystic fibrosis. Fertil Steril 2006, 85:1484-1487.

30. Balen AH, Laven JS, Tan SL, Dewailly D: Ultrasound assessment of the polycystic ovary: international consensus definitions. Hum Reprod Update 2003, 9:505-514

31. Dusek A, Bartos L: Variation in Ano-genital distance in spontaneously cycling female mice. Reprod Domest Anim, in press.

32. Tietze C: Differential fecundity and effectiveness of contraception. Eugen Rev 1959, 50:231-237.

33. Bánszegi $O$, Szenczi P, Dombay K, Bilkó A, Altbäcker V: Anogenital distance as a predictor of attractiveness, litter size and sex ratio of rabbit does. Physiol Behav 2012, 105:1226-1230.

34. Monclús R, Blumstein DT: Litter sex composition affects life-history traits in yellow-bellied marmots. J Anim Ecol 2012, 81:80-86.

35. Abbott DH, Barnett DK, Bruns CM, Dumesic DA: Androgen excess fetal programming of female reproduction: a developmental aetiology for polycystic ovary syndrome? Hum Reprod Update 2005, 11:357-374.

36. Forsdike RA, Hardy K, Bull L, Stark J, Webber LJ, Stubbs S, Robinson JE, Franks S: Disordered follicle development in ovaries of prenatally androgenized ewes. J Endocrinol 2007, 192:421-428.
37. Sloboda DM, Hickey M, Hart R: Reproduction in females: the role of the early life environment. Hum Reprod Update 2011, 17:210-227.

38. Sir-Petermann T, Maliqueo M, Angel B, Lara HE, Perez-Bravo F, Recabarren SE: Maternal serum androgens in pregnant women with polycystic ovarian syndrome: possible implications in prenatal androgenization. Hum Reprod 2002, 17:2573-2579.

39. Sir-Petermann T, Codner E, Maliqueo M, Echiburú B, Hitschfeld C, Crisosto N, Pérez-Bravo F, Recabarren SE, Cassorla F: Increased anti-mullerian hormone serum concentrations in prepubertal daughters of women with polycystic ovary syndrome. J Clin Endocrinol Metab 2006, 91:3105-3109.

40. Scheffer GJ, Broekmans FJ, Bancsi LF, Habbema JD, Looman CW, Te Velde ER: Quantitative transvaginal two- and three-dimensional sonography of the ovaries: reproducibility of antral follicle counts. Ultrasound Obstet Gynecol 2002, 20:270-275.

41. Bancsi LF, Broekmans FJ, Looman CW, Habbema JD, te Velde ER: Impact of repeated antral follicle counts on the prediction of poor ovarian response in women undergoing in vitro fertilization. Fertil Steril 2004, $81: 35-41$.

42. Skakkebæk NE, Rajpert-De Meyts E, Main KM: Testicular dysgenesis syndrome: an increasingly common developmental disorder with environmental aspects. Hum Reprod 2001, 16:972-978.

43. Sharpe RM, Skakkebaek NE: Testicular dysgenesis syndrome: mechanistic insights and potential new downstream effects. Fertil Steril 2008, 89:33-38.

44. Buck Louis GM, Cooneya MA, Peterson CM: The ovarian dysgenesis syndrome. J Dev Orig Health Dis 2011, 2:25-35.

doi:10.1186/1476-069X-11-90

Cite this article as: Mendiola et al:: Anogenital distance is related to ovarian follicular number in young Spanish women: a cross-sectional study. Environmental Health 2012 11:90

\section{Submit your next manuscript to BioMed Central and take full advantage of:}

- Convenient online submission

- Thorough peer review

- No space constraints or color figure charges

- Immediate publication on acceptance

- Inclusion in PubMed, CAS, Scopus and Google Scholar

- Research which is freely available for redistribution 